\title{
Multiple pterygium-malignant hyperthermia syndrome
}

INSERM

\section{Source}

INSERM. (1999). Orphanet: an online rare disease and orphan drug data base. Multiple pterygium-malignant hyperthermia syndrome. ORPHA:2215

Malignant hyperthermia-arthrogryposis-torticollisis an extremely rare arthrogryposis syndrome, described in only two pairs of siblings from two unrelated families to date, and characterized by the association of arthrog ryposis, congenital torticollis, dysmorphic facial features (i.e. asymmetry of the face, myopathic facial movements, ptosis, posteriorly rotated ears, cleft palate), progressive scoliosis and episodes of malignant hyperthermia. There have been no further descriptions in the literature since 1988. 